\title{
A Semi-Physiologically Based Pharmacokinetic Model Describing the Altered Metabolism of Midazolam Due to Inflammation in Mice
}

\author{
Ninad Varkhede ${ }^{1}$, Nita Patel ${ }^{2}$, William Chang ${ }^{3}$, Kenneth Ruterbories ${ }^{4}$, M. Laird Forrest ${ }^{1}$ \\ ${ }^{1}$ Department of Pharmaceutical Chemistry, The University of Kansas 2095 Constant Ave, \\ Lawrence, Kansas 66047, USA \\ ${ }^{2}$ Drug Disposition, Lilly Corporate Center, Eli Lilly and Company Indianapolis, Indiana 46285, \\ USA \\ ${ }^{3}$ Lilly Biotechnology, Eli Lilly and Company San Diego, California 92121, USA \\ ${ }^{4}$ Bioanalysis and Biotransformation, Research and Development, AbbVie North Chicago, Illions, \\ USA
}

\begin{abstract}
Purpose-To investigate influence of inflammation on metabolism and pharmacokinetics (PK) of midazolam (MDZ) and construct a semi-physiologically based pharmacokinetic (PBPK) model to predict PK in mice with inflammatory disease.

Methods-Glucose-6-phosphate isomerase (GPI)-mediated inflammation was used as a preclinical model of arthritis in DBA/1 mice. CYP3A substrate MDZ was selected to study changes in metabolism and PK during the inflammation. The semi-PBPK model was constructed using mouse physiological parameters, liver microsome metabolism, and healthy animal PK data. In addition, serum cytokine, and liver-CYP (cytochrome P450 enzymes) mRNA levels were examined.
\end{abstract}

Results-The in vitro metabolite formation rate was suppressed in liver microsomes prepared from the GPI-treated mice as compared to the healthy mice. Further, clearance of MDZ was reduced during inflammation as compared to the healthy group. Finally, the semi-PBPK model was used to predict PK of MDZ after GPI-mediated inflammation. IL-6 and TNF-a levels were elevated and liver-cyp3al 1 mRNA was reduced after GPI treatment.

Conclusion-The semi-PBPK model successfully predicted PK parameters of MDZ in the disease state. The model may be applied to predict PK of other drugs under disease conditions using healthy animal PK and liver microsomal data as inputs.

M. Laird Forrest lforrest@ku.edu.

COMPLIANCE WITH ETHICAL STANDARDS

Conflict of Interest None to declare.

Electronic supplementary material The online version of this article (https://doi.org/10.1007/s11095-018-2447-9) contains supplementary material, which is available to authorized users. 


\section{Keywords}

cytokines; drug metabolism; glucose-6-phosphate isomerase; inflammation; physiologically based pharmacokinetic model

\section{INTRODUCTION}

Inflammation and other disease conditions are known to alter the expression of cytochrome P450 enzymes (CYPs) due to increased proinflammatory cytokine levels $(1,2)$. Typically, cytokines such as IL-6, IL-1 $\beta$, IFN- $\gamma$ and TNF- $\alpha$ are increased during inflammation. Elevated cytokine levels can lead to suppression of various CYPs. Increased IL-6 levels downregulate CYP3A4, while TNF-a downregulates CYP2C19 (3-5). Thus, inflammation and elevated cytokine levels may cause disease-drug interactions by altering the pharmacokinetics (PK) and specifically clearance of drugs that are metabolized by CYPs.

Cytokine-mediated CYP suppression is believed to occur through a nuclear receptor, hepatic nuclear factor-4a (HNF-4a). Elevated IL-6, TNF- $\alpha$ and IL-1 $\beta$ can inhibit the action of HNF-4a. HNF-4a is involved in the regulation of pregnane X receptor (PXR) and constitutive androstane receptor (CAR) that are responsible for regulating the expression of CYP3A4 following exposure to some xenobiotics (4). Elevated IL-6 is known to downregulate CYP3A4, CYP2C9, CYP2C19 and CYP1A2, while TNF-a down-regulates CYP2C19 $(3,6)$. In this study, the hypothesis was that the elevated cytokines during inflammation (diseased state) would suppress the expression of mouse cyp3a11 (76\% amino add homology with the human CYP3A4) (7), which may lead to changes in PK of its substrates.

In the case of glucose-6-phosphate isomerase (GPI)-mediated inflammation in DBA/1 mice, circulating levels of IL-6 and TNF- $a$ were increased (8). This GPI model of inflammation is frequently used to test the anti-inflammatory activity of new chemical entities (NCEs) (9). The PK of NCEs is generally studied using healthy mice, and the data are often used to inform dose selection for demonstration of efficacy in an inflammation model. Therefore, it is worthwhile to develop a mechanistic approach, which includes the CYP activity differences in healthy versus diseased mice, to inform dose selection for the pharmacological assays utilizing the GPI model. The overall goal of this study was to build a model for dose selection, which can more accurately predict dose response in the diseased state based off healthy animal-PK data and in vitro metabolism data (healthy and diseased).

Midazolam (MDZ), a known CYP3A4 substrate, was selected as a model compound for in vitro metabolism and PK studies. Lipopolysaccharide- $(10,11)$ and carrageenan-induced inflammation (12) both have been reported to alter the PK of MDZ. Metabolism of MDZ was evaluated using liver microsomes prepared from healthy and GPI-treated mice. According to the published in vitro experiments in humans and rodents, MDZ is mainly metabolized by CYP3A to form 1-OH-MDZ and 4-OH-MDZ. The phase 1 metabolites of MDZ may be further conjugated with glucuronide to form 1-OH-MDZ-glucuronide and 4OH-MDZ-glucuronide. In a PK study using chimeric mice with humanized livers (PXB mice), 1-OH-MDZ, 4-OH-MDZ, 1,4-diOH-MDZ, and 1-OH-MDZ-glucuronide were 
detected in plasma. However, 4-OH-MDZ and 1-OH-MDZ-glucuronide were not detected in severe combined immune deficient (SCID) mice (10,13-15).

In this work, a semi-physiologically based pharmacokinetic (PBPK) model was constructed to predict PK of MDZ in mice with GPI-mediated inflammation. The model equations and methodology could be applied to other drugs to predict altered PK parameters in disease models using a limited data set, including healthy-animal PK data and in vitro liver microsome studies.

\section{METHODS}

The methods section is divided into various subsections describing the in vitro metabolism, PK, Liquid Chromatography-Mass Spectrometry (LC-MS) analysis, semi-PBPK model, and quantitation of cytokines and mRNA Briefly, the rate of 1-OH-MDZ formation in the liver microsomes was used to assess the degree of inflammation-mediated suppression of MDZ metabolism. In addition, MDZ PK parameters were compared in the healthy and GPI-treated mice. Finally, both the in vitro (in healthy and GPI mice) and PK data (in healthy mice) were used to build the semi-PBPK model. The in vitro microsomal data defined metabolism of MDZ from the liver and intestines, while the parameters associated with a 2-compartment model were estimated using the healthy animal PK data. These estimated PK parameters were used to define the central and peripheral compartments of the semi-PBPK model (Fig. 1). The 2-compartment model PK parameters from GPI mice were used to illustrate that the PK in the diseased state can be predicted using in vitro (healthy and diseased animals) and healthy animal PK data. In addition, serum cytokine levels were measured in the healthy mice and on days 12 and 21 after GPI treatment. The mRNA-levels of cyp3all, cyp2c29 and cyp2d26 in liver were also measured on days 1, 5, 8 and 15 after GPI treatment.

\section{Animals}

Male DBA/1 mice (Harlan Laboratories, Indianapolis, IN) were acclimatized for 3 days and housed as 4 animals per cage or individually if a cage mate was not available. Animals were approximately 9-10 weeks old at the start of the study. A 12-h light and 12-h dark cycle was maintained throughout the study. Mice were fed and given access to water ad libitum. All procedures were in compliance with the Guide for the Care and Use of Laboratory Animals: Eighth Edition, (Institute for Laboratory Animal Research, The National Academies Press, Washington, D.C.); and the National Institutes of Health, Office of Laboratory Animal Welfare (NIH publication no. 85-23, revised 1985). Whenever possible, procedures were designed to avoid or minimize discomfort, distress, and pain to the animals.

\section{GPI Treatment}

The mice were treated with GPI according to a previously published protocol with a few modifications (16). Briefly, a 4-mg/mL solution of recombinant human GPI was mixed with an equal volume of complete Freund's adjuvant This final $2 \mathrm{mg} / \mathrm{mL}$ solution of GPI was used for the treatment. A $100-\mu \mathrm{L}(200-\mu \mathrm{g})$ injection of the above solution was administered at both sides of the tail base to induce inflammation. 


\section{Preparation of Mouse Liver Microsomes (MLM) and In Vitro Experiments}

Healthy and diseased mice were sacrificed using cardiac puncture either immediately or on day 12 after the GPI treatment, and the livers were collected and stored at $-80^{\circ} \mathrm{C}$ until immediately before use. The MLM were prepared using previously reported protocols $(17,18)$. The protein content of MLM was measured using the bidnchoninic add assay using a reported procedure (19). Liver microsome kinetic studies of 1-OH-MDZ and 4-OH-MDZ formation were carried out by following the reported methods $(13,15,20)$. Based on the linear relationship of MDZ metabolism and MLM protein concentration from 0.1 to 0.5 $\mathrm{mg} / \mathrm{mL}$ (data not shown), a protein content of $0.1 \mathrm{mg} / \mathrm{mL}$ was selected for all subsequent microsomal experiments. A 2-min incubation time was selected for kinetic experiments based on an earlier study, which reported that the incubation time for formation of the metabolites was linear up to 20 min using MLM and human liver microsomes (HIM) (20). The rate of 1-OH-MDZ and 4-OH-MDZ formation was measured at concentrations of MDZ ranging from 0 to $250 \mu \mathrm{M}$. The data obtained was fitted to a substrate inhibition kinetics using GraphPad Prism 6 (GraphPad Software Inc., La jolla, CA).

\section{Pharmacokinetics of MDZ}

MDZ was administered via intravenous (IV) or oral (PO) routes at $1 \mathrm{mg} / \mathrm{kg}$ or $5 \mathrm{mg} / \mathrm{kg}$, respectively. The PO bioavailability of MDZ was low $(\mathrm{F}=0.023)$ according to the previously published report (21). Therefore, a higher PO dose was selected. Approximately $20 \mu \mathrm{L}$ of blood was collected using a capillary and applied directly on dried blood spot (DBS) cards at time points as follows: IV- 0.08, 0.166, 0.33, 0.5, 1, 2, 4, 6,8 $\mathrm{h}$ and PO$0.166,0.33,0.5,1,2,4,6,8 \mathrm{~h}$. The DBS samples were analyzed for MDZ, 1-OH-MDZ, 4-OHMDZ and 1-OH-MDZ-glucuronide. The MDZ used for dosing in the PK studies was obtained from Hospira (Lake Forrest, IL). The MDZ, 1-OH-MDZ and 4-OH-MDZ standards were obtained from Cerilliant Corporation (Round Rock, TX), while the 1-OH-MDZglucuonide standard was obtained from Toronto Research Chemicals (Ontario, Canada).

Pharmacokinetics of MDZ in the healthy and diseased mice were compared using 3 animal groups as shown in the Supplementary Fig. 1. The first group was not treated with GPI and was kept for 21 days before MDZ dosing and DBS sample collection. The second group was treated with GPI on day 10 of the study, while the third group was treated with GPI on day 1. Finally, MDZ was administered on day 21, and DBS samples were subsequently collected to measure blood concentration of the analytes (MDZ, 1-OH-MDZ, 4-OH-MDZ and 1-OHMDZ-glucuronide). The healthy and diseased animal PK parameters were obtained using non-compartmental analysis (NCA) using SimBiology (Matlab R2017a). Analysis of variance (ANOVA) and Tukey's comparison test were used to determine differences in PK parameters in healthy and diseased mice.

\section{Measurement of Fraction Unbound in Plasma and Liver Microsomes}

The fraction unbound MDZ to the proteins in the plasma and liver microsomes was determined at $37^{\circ} \mathrm{C}$ using a $\mathrm{HT}$ dialysis micro equilibrium device with a $12-14 \mathrm{kDa}$ molecular weight cutoff (Gales Ferry, CT) in a stirred $37^{\circ} \mathrm{C}$ bath The microsomal protein concentration was $0.5 \mathrm{mg} / \mathrm{mL}$ in phosphate buffer (100 mM, pH 7.4), and the plasma was thawed on the day of use and adjusted to $\mathrm{pH} 7.4$ using phosphoric add. The samples were 
collected from both the protein side and buffer side of the membrane after 0 and $4.5 \mathrm{~h}$. The signal for MDZ was monitored by LC-MS/MS with a calibration curve range from 1 to 5000 $\mathrm{nM}$ and an acceptable interference peak less than $25 \%$ of the lower limit of quantitation. Deviations of less than $\pm 30 \%$ were acceptable for the calibration curve samples. Fraction unbound was calculated as a ratio of MDZ concentration in the buffer and protein chambers. Percent recovery (data not shown) was calculated by dividing the sum of the buffer and protein chambers by the time 0 concentration.

\section{Liquid Chromatography-Mass Spectrometry (LC-MS) Analysis of DBS Samples}

Analysis of MDZ and its metabolites was performed using a previously published protocol with modifications as described (22). Stock solutions of each analyte were combined and serially diluted to produce a range of working solutions, which were used to fortify control mouse blood to yield calibration standards ( 1 to $10,000 \mathrm{ng} / \mathrm{mL}$ ). These calibration standards were then spotted onto DBS cards and allowed to dry at room temperature. A 3-mm punch of each study and standard DBS sample was removed and placed in separate wells of 96well plates, then extracted with a methanol/acetonitrile $(1: 1, \mathrm{v} / \mathrm{v})$ solution containing internal standards. The resulting extracts were analyzed using an ABSdex API4000 triple quadrupole mass spectrometer LC-MS/MS instrument (Applied Biosystems/MDS; Foster City, CA) run in positive ion mode using a ThermoFisher Betasil C18 $2 \times 20-\mathrm{mm} 5-\mu \mathrm{m}$ HPLC column (ThermoFisher Scientific, Waltham, MA) with $0.1 \%$ formic add/water and an acetonitrile gradient to achieve the chromatographic separation. Each compound was detected and quantified with analyte specific selected reaction monitoring (SRM) $(\mathrm{M}+\mathrm{H})^{+}$transitions (MDZ: $\mathrm{m} / \mathrm{z} 326.1$ > 291.2, 1-OH-MDZ: $\mathrm{m} / \mathrm{z} 342.1>203.2,4-\mathrm{OH}-\mathrm{MDZ}: \mathrm{m} / \mathrm{z} 342.1>234.2$, 1-OH-MDZ-glucuronide: $\mathrm{m} / z 518.2>324.1, \mathrm{D}_{4}$-MDZ: $\mathrm{m} / z 330.1>295.2$, and $\mathrm{D}_{4}-1-\mathrm{OH}-$ MDZ: $m / z 346.1>328.1)$. The mass spectrometer quadrupoles were tuned to achieve unit resolution (0.7 Da at 50\% FWHM) and data were acquired and processed with Analyst 1.4.2 (Applied Biosystems/MDS). The limit of detection was set at 5-fold greater than the noise. The lower limit of quantitation was $5 \mathrm{nM}$ for MDZ, 1-OH-MDZ and 4-OH-MDZ.

\section{LC-MS Analysis of the In Vitro Samples}

The in vitro metabolism samples were analyzed by LC-MS/MS using an ABSdex QTrap 6500 triple quadrupole mass spectrometer (Applied Biosystems/MDS; Foster City, CA) equipped with a TurboIonSpray interface and operated in a positive ion mode. The analytes were separated using an Ace Ultracore SuperC18 column $(2.1 \times 30-\mathrm{mm}, 5-\mu \mathrm{m})$ with a gradient elution of 5-mM ammonium bicarbonate and acetonitrile. Each compound was detected and quantified by analyte specific SRM $(\mathrm{M}+\mathrm{H})^{+}$transitions (1-OH-MDZ: $\mathrm{m} / \mathrm{z}$ $342.1>203.0$, 4-OH-MDZ: $\mathrm{m} / \mathrm{z} 342.1>234.0$, and $\mathrm{D}_{4}-\mathrm{l}$ - OH-MDZ: $\mathrm{m} / \mathrm{z} 346.1>203.0$ ). The mass spectrometer quad-rupoles were tuned to achieve unit resolution $(0.7 \mathrm{Da}$ at $50 \%$ FWHM) and data were acquired and processed with Analyst 1.6 (Applied Biosystems/ MDS).

\section{Construction of the Semi-PBPK Model}

The semi-PBPK model with a 2-compartment PK model was constructed using SimBiology (Matlab R2017a) (Fig. 1). The mouse physiological parameters obtained from literature (2326), experimental values and the 2-compartment model estimated parameters (Tables IV, V 
and Supplementary Table I) were used to construct the semi-PBPK model. The volumes of the central and peripheral compartments and rate constants for transfer of MDZ between the central and peripheral compartments were estimated by fitting the healthy-animal IV PK data with the 2-compartment PK model. 'Nonlinear mixed-effects problems' was used as the estimation method for the 2-compartment model fitting. The in vitro kinetic data for 1-OHMDZ and 4-OH-MDZ formation were used in the semi-PBPK model to define the rate of hepatic metabolism, while the literature data were used for the gut metabolism (Table V)

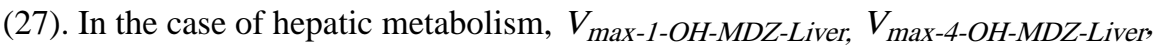
$K_{m-1-O H-M D Z \text {-Liver }}$ and $K_{m-O H-M D Z-L i v e r}$ values in both the healthy and the diseased animals were obtained experimentally and a $V_{\text {max-1-OH-MDZ-Liver-Heaithy }} / V_{\text {max-1-OH-MDZ-Liver-GPI }}$ ratio (0.55) was calculated (Table V). Experimental in vitro data were not available for gut metabolism, therefore literature values were used (27). It was assumed that the $V_{\text {max-1-OH-MDZ-gW-Healthy }} / V_{\max -1-O H-M D Z-g_{W-G P I}}$ ratio for intestine was same as that for the hepatic metabolism. The values of gut $V_{\max -1-O H-M D Z-g_{W}}$ and $V_{\max -4-O H-M D Z-g_{W}}$ for day 12 GPI mice were calculated using the ratio 0.55. Scaling of $V_{\text {max-1/4-OH-MDZ-Liver }}$ and $V_{\text {max-1/4-OH-MDZ- }{ }_{W}}$ was done for the entire liver and intestine, respectively so that the values could be used in the semi-PBPK model. A scaling factor of $45 \mathrm{mg}$ of liver microsomal protein per gram of mouse liver was used as mentioned in the previous report (28). For the intestinal $V_{\text {max-1/4-OH-MDZ- } g_{W}}$ scaling, $23.6 \mathrm{mg}$ of intestinal microsomal protein per gram of intestine was used (29). CYP3A is almost exclusively responsible for metabolism of MDZ to form hydroxylated metabolites (20,27). However, additional nonCYP3A metabolism in the gut was estimated by fitting the PO healthy animal PK data to the semi-PBPK model. This additional metabolism was defined by $V_{\text {max-non VZCYP3A-MDZ- } g_{W}}$ and $K_{m-n o n C T P 3 A-M D Z-g_{W}}$ (Table V). Similar to previously mentioned gut $V_{\max .1 . O H-M D Z-{ }_{W}}$ calculations, the ratio of 0.55 was used to calculate $V_{\text {max-1-nonCYP3A-MDZ- } g_{W}}$ for GPI treated mice, while $K_{m-n o n C Y p 3 A-M D Z-g_{W}}$ was assumed as constant for the healthy and disease condition.

Sensitivity analysis was performed on the model input parameters as shown in Supplementary Figs. 9 and 10. The model parameters were altered by -100 to $+500 \%$ of the original values listed in Tables IV and V.

The semi-PBPK model was adopted from a previously published study by Zhang et al. (30). The model can be described by eqs. 1 to 6 (Supplementary material), which were solved by the solver type 'Ordinary differential equations (ODE) 15s' (stiff/NDF). Eq. 1 represents absorption of MDZ through the gut lumen. Eqs. 2 and 5 defines MDZ metabolism in the intestine and liver, respectively. Eq. 3 is the 'Well-Stirred' gut model (31), which was used in eq. 2 for calculation of fraction unbound in gut $\left(f_{u, g}\right)$. Eq. 4 defines the transit of MDZ from the intestine and central compartment to the portal vein and then to the liver. The transfer of MDZ from the liver to central compartment and further exchange with the peripheral compartment is shown in eq. 6. $C_{g w}, C_{p v}, C_{l i v}, C_{c e n}, C_{p e r}$ are concentration (nmol/L) of MDZ in gut wall, portal vein, liver, central compartment and peripheral compartment, respectively. $A_{g l}$ is the amount (nmol) of MDZ in the gut lumen compartment All other parameters in the eqs. 1 to 6 are mentioned in Tables IV and V. Assumptions in the semiPBPK model are described as follows, a) The in vitro literature data used to define intestinal metabolism of MDZ was applicable to the semi-PBPK model (27). b) Suppression of 
intestinal CYP450 activity due to the GPI-mediated inflammation was same as in the liver, c) The mouse physiological parameters (blood flows, organ volumes) were same for the healthy and GPI treated diseased mice.

\section{Quantitation of Serum Cytokines}

Serum cytokines were quantitated using a mouse proinflammatory multiplex kit (Meso Scale Diagnostics, Rockville, MD) (34). Briefly, serum samples were diluted 2-fold with diluent, and $50 \mu \mathrm{L}$ of diluted sample was added to each well on a pro-inflammatory panel plate (96well) and incubated for $2 \mathrm{~h}$ at room temperature. After washing 3 times with the wash buffer, $25 \mu \mathrm{L}$ of detection antibody solution was added per well, followed by an additional 2-h incubation at room temperature. The wells were washed 3 times with the wash buffer, and $150 \mu \mathrm{L}$ of $2 \mathrm{X}$ Read Buffer $\mathrm{T}$ was added to each well. The plate was immediately read on a MSD Sector S 600 (Meso Scale Diagnostics, Rockville, MD). Sample concentrations were calculated using calibration curves that were fitted using a 4-parameter logistic model with a $1 / \mathrm{Y}^{2}$ weighting. ANOVA was used to establish statistical differences in cytokine levels for the healthy and diseased mice.

\section{RNA Isolation and Cyp mRNA Level Detection by Quantitative Polymerase Chain Reaction (qPCR)}

For each animal, 50-150 mg of frozen liver tissue was homogenized in the presence of 800 $\mu \mathrm{L}$ of Trizol ${ }^{\mathrm{TM}}$ (Thermo Fisher Scientific, Waltham, MA) using FastPrep ${ }^{\circledR}$ lysing matrix D beads and the FastPrep ${ }^{\circledR}-24$ homogenizer (MP Biomedicals, Santa Ana, CA). The homogenate was chilled on ice and was clarified by centrifugation $(10,000 \times \mathrm{g}$ for $4 \mathrm{~min})$. The clarified homogenate was mixed with an equal volume of $100 \%$ ethanol, and then processed using the Direc-Zol ${ }^{\mathrm{TM}}$ RNA isolation spin column protocol, including DNAse 1 treatment (Zymo Research, Irvin, CA). The concentration and yields of the purified total liver RNA were determined using a Nanodrop ${ }^{\mathrm{TM}} 8000$ spectrophotometer. Then $100 \mathrm{ng}$ of purified RNA was used in a reverse transcription reaction to generate cDNA using TaqMan ${ }^{\circledR}$ High Capacity RNA-to-cDNA Kit (Applied Biosystems, Foster City, CA). The cDNA reaction was diluted 5-fold with sterile water and used for TaqMan® based quantitative PCR analysis for cyp3al 1, cyp2c29, and cyp2d26 mRNA targets as well as for the PPIB housekeeping gene mRNA normalizer control. The qPCR data were collected on a 7900HT Real Time PCR instrument (Applied Biosystems). The data were analyzed using ExpressionSuite ${ }^{\circledR}$ software (Thermo Fisher Scientific, Waltham, MA), and cyp target mRNA levels were expressed relative to the PPIB mRNA normalizer control. The unpaired T-test was used to establish statistical differences between day-1 and -12 cyp mRNA levels.

\section{Statistical Analysis}

Chi square test was used to find association between predicted and observed PK profiles using Excel Chi square test function (35). ANOVA, T-test, Tukey's multiple comparison test were performed using GraphPad Prism 6 (LaJolla, CA). Box-plots for cytokines and cypmRNA were plotted using RStudio (Version 1.1.383). 


\section{RESULTS}

\section{Effect of GPI-Mediated Inflammation on the In Vitro Metabolism of MDZ}

The rate of 1-OH-MDZ formation was higher in the MLM prepared from heathy mice as compared to the MLM prepared from GPI-treated mice (Fig. 2 and Table I). The

$V_{\text {max-1-OH-MDZ-Liver }}$ was suppressed by $44 \%$ in the diseased mice-MLM as compared to the healthy. The $V_{\text {max-1-OH-MDZ-Liver }}$ was $2.047( \pm 0.005) \mathrm{nmol} / \mathrm{min} / \mathrm{mg}$ in MLM of the healthy mice and $1.143( \pm 0.021) \mathrm{nmol} / \mathrm{min} / \mathrm{mg}$ in MLM of the GPI treated mice ( $P$ value $\$ 0.0001)$. This indicated that the GPI-mediated inflammation suppressed cyp3al 1 expression, leading to lower $V_{\text {max-1-OH-MDZ-Liver }}$ However, $K_{\text {max-1-OH-MDZ-Liver }}$, was relatively unchanged ( $P$ value $=0.151)$ in the MLM prepared from the healthy versus diseased mice. In the case of 4OH-MDZ, both $V_{\max -1-O H-M D Z-L i v e r}$ and $K_{m-4-O H-M D Z-L i v e r}$ were suppressed with the MLM prepared from the diseased animals as compared to healthy animals ( $P$ value $₫ 0.0001)$ (Fig. 2 and Table II). The higher $K_{m-4-O H-M D Z-L i v e r}$ as compared to $K_{m-1-O H-M D Z-L i v e r}$ suggested that 4-OH-MDZ formation is a minor route of metabolism as compared to 1-OH-MDZ ( $P$ value $\$ .0001)$. Similar results concluding lower contribution of 4-OH-MDZ as compared to 1-OH-MDZ were reported earlier $(13,15)$.

\section{Pharmacokinetics of MDZ in Healthy and GPI-Treated Mice}

In the case of IV dosing, plasma MDZ profiles were available through $2 \mathrm{~h}$ for healthy and day 21 GPI mice, while for day 12 mice, plasma MDZ levels were available through $4 \mathrm{~h}$ (Fig. 3). In the case of PO dosing, for day 12 and 21, PK were available through $8 \mathrm{~h}$, while for PO dosing in healthy mice, data were available through $2 \mathrm{~h}$. In the case of PO dosing on day 12, inter-individual variability in the PK parameters (Table III, Supplementary Figs. 2 and 3) was high. This inter-individual variability may be due to variability in the IL-6 levels (2700 to $6900 \mathrm{pg} / \mathrm{mL}$ ) (Fig. 5) on day 12 leading to differences in the CYP suppression and PK of MDZ. Supplementary Figs. 4 and 5 describe PK profiles of 1-OH-MDZ and 4-OHMDZ, respectively after IV and PO MDZ administration. The $\mathrm{AUC}_{0-8 \mathrm{~h}}$ of 1-OH-MDZ after IV and PO administration of MDZ is shown in Supplementary Fig. 6. Fraction unbound in plasma $\left(f_{u, p}\right)$ for both the healthy and diseased states was measured and was same for both of these samples (Table IV).

The IV MDZ clearance decreased by 0.5 -fold on day 12 after GPI treatment as compared to the healthy mice ( $P \leq 0.05$ ) (Table III and Supplementary Fig. 2$)$. By Day 21, the clearance in GPI-treated mice had still not returned to values observed in the healthy animals, although the differences were not significant $(P=0.179)$. In the case of the PO MDZ administration, the day 12 GPI clearance/F was 0.4 -fold lower than that of the healthy mice $(\mathrm{P} \leq 0.05)$ (Supplementary Fig. 3).

\section{Prediction of MDZ PK in GPI-Treated Mice Using the Semi-PBPK Model}

The Chi square test was used to compare observed PK profile with the predicted profile (Fig. 4). For IV MDZ dosing, the observed and predicted healthy-animal PK profiles were similar with a Chi square test $p$-value of 0.999 . While, day 12 observed and predicted PK profiles were similar with the Chi square test p-value was 0.996. In the case of PO MDZ dosing, predicted and observed profiles in the healthy mice had a Chi square test $p$-value of 0.999 , 
while day $12 \mathrm{PK}$ profiles had Chi square test $p$-value of 0.964 . This indicated that the semiPBPK model successfully predicted the PK after GPI treatment In addition, $\mathrm{AUC}_{0-8 \mathrm{~h}}$ and clearance values of MDZ showed good agreement between predicted versus observed values for both the IV and PO MDZ administration. The mean observed values of the PK parameters and the $95 \%$ confidence interval were compared with the predicted PK parameter values. All the predicted PK parameters resided within the 95\% confidence intervals of the observed data (Supplementary Figs. 7 and 8). In the case of PK predictions after PO dosing on day 12 (Fig. 4), a visual check showed that the data points after $4 \mathrm{~h}$ were not well correlated with the predicted profile. This was due to the lack of good terminal phase for the day 12 PO-PK profile.

\section{Sensitivity Analysis}

The $C_{\max }$ was sensitive to both $V_{\max -1-O H-M D Z \text {-Liver }}$ and $K_{\text {m-1-OH-MDZ-Liver }}$ after PO MDZ administration as demonstrated in the Supplementary Fig. 9. $C_{\max }$ decreased with increasing $V_{m-1-O H-M D Z-L i v e r}$ while increased with increasing $K_{m-1-O H-M D Z \text {-Liver }}$

In addition, altered values of $V_{\max -1-O H-M D Z-g_{W}} V_{\text {max-NonCYP3A-MDZ-gW }}$ $K_{m-N o n C Y P 3 A-M D Z-g_{W}} F_{g}$ and $F_{u, b}$ lead to changes in $C_{m a x}$ and overall PK profile of MDZ after PO dosing as shown in the Supplementary Fig. 10.

\section{Effect of GPI-Mediated Inflammation on Serum Cytokine Levels}

The cytokine levels peaked on day 12 according to previous experiments (data not shown). In this study, the healthy mice had lower cytokine levels as compared to the day 12 GPI treated mice (Fig. 5). Since inflammation in this model remits over time (data not shown), the cytokine levels returned to the normal range by day 21 , but did not full return to the prestudy levels. Serum levels of various other cytokines (IL-2, IL-i $\beta$, IL-10, IFN- $\gamma$ ) were not significantly elevated on day 12 after GPI treatment (data not shown). IL-6 levels in the GPItreated mice on day 12 were approximately 100 -fold higher than that in the healthy mice $(P$ $\leq 0.0001$ ). In addition, day 12 IL-6 levels were 5.4-fold higher than that on day 21 ( $P \leq$ $0.0001)$. However, healthy animal and day $21 \mathrm{IL}-6$ levels were not significantly different. Serum TNF-a levels were 2.6-fold higher in diseased animals on day 12 as compared to levels in the healthy mice (P $\mathbf{3} .0001$ ). Day 12 TNF-a levels were also higher (1.3-fold) than levels on day 21 (P $₫$ ).01). In the case of TNF-a, day 21 levels were 1.9-fold higher than healthy $(\mathrm{P} \leq 0.0001)$.

\section{Effect of GPI-Mediated Inflammation on Liver cyp3a11, cyp2c29 and cyp2d26 mRNA}

The mRNA levels of cyp3all, cyp2c29, and cyp2d26 were normalized to the house-keeping gene PPIB (Fig. 6). Cyp2c66 mRNA was not found in this study, while cyp2c29 had the highest basal levels of mRNA expression followed by cyp3a11 and cyp2d26. The responses of cyp3al 1 and cyp2c29 to GPI-mediated inflammation were similar. The mRNA levels were highest on day 1 after GPI treatment, followed by a reduction in levels on day 5 , and 12 as compared to the baseline levels. However, in the case of cyp3al 1 and cyp2c29, day 8 showed surprisingly increased mRNA levels. On day 15, mRNA levels appeared to increase but did not return to the baseline levels. The reduction of mRNA levels was notably highest on day 5. Cyp3al 1 mRNA on day 12 was suppressed by around $89 \%$ after the GPI 
treatment. On day 12 , cyp2c29 and cyp2d26 mRNA were suppressed by around 85 and 51\%, respectively as compared to the day 1 levels.

\section{DISCUSSION}

In this study, the in vitro metabolism and PK of MDZ was studied to demonstrate suppression of the CYP activity in the GPI-treated animals, and a semi-PBPK model was generated using in vitro data from both the healthy and diseased animals. It was assumed that the 2-compartment IV parameters of the healthy and diseased mice were same. Therefore, the IV-PK data from the healthy mice were used to generate the 2-compartmental parameters for both of the groups. The 2-comparment model parameters for the diseaseanimal IV data were also available and used for the model prediction (data not shown). However, this did not change the results significantly.

The GPI mouse model is frequently used to induce arthritis and study the anti-inflammatory activity of NCEs in the drug discovery process (9). In this study, the GPI-mediated inflammation increased serum proinflammatory cytokine levels in the DBA/1 mice. This result was in agreement with the previously published report (8). Several published in vitro and in moo models of inflammation showed that increased cytokines can lead to reduced CYP expression $(10,11,36)$.

The GPI model showed highest degree of inflammation approximately on the day 12 and the inflammation decreased afterwards (data not shown). Therefore, the day 8-CYP mRNA levels should be lower as compared to the day 1-levels based on the disease state. Current study shows that the mean cyp3a11 and cyp2c29 mRNA levels on day 8 were surprisingly higher as compared to the day 5 and 12 (Fig. 6). However, the day 8-cyp3all mRNA levels were not significantly different when compared to the day $5(p=0.1)$ and day $12(p=0.13)$. In the case of cyp2c29 mRNA, day 8 and day 12 levels were not significantly different $(p=$ $0.054)$, however, the day $8 \mathrm{mRNA}$ levels were significantly higher $(p=0.026)$ than the day 5 (Unpaired T-test). Although the day 8 mRNA levels could not be completely explained, day 12 data were more important for the comparison. Because, CYP mRNA and cytokine levels, in vitro metabolism and PK for day 12 after GPI treatment were available for day 12 after GPI treatment. Therefore, the conclusions were based on the day 12 data.

The IL- 6 and TNF- $a$ proinflammatory cytokine levels increased on day 12 after GPI treatment. Cyp3a11 levels decreased on day 5 and 12 after GPI treatment The reduction in $V_{\text {max-1OH-MDZ-Livcr }}(P \leq 0.0001)$ indicated that the CYP activity was suppressed. In this report, the GPI-mediated inflammation was studied based on increased cytokines, decreased CYP mRNAs, decreased in vitro metabolism, and decreased clearance of MDZ. The experimental data may be useful for future experiments with GPI-mediated mouse model of inflammation. Another in vitro study using human hepatocytes showed that IL-6 was responsible for suppression of various CYP-mRNA, including CYP3A4. In addition, activities of CYP3A4 and CYP1A2 were also suppressed (37). This suppression of CYPs may lead to alteration of PK of its substrates. Machavaram et al. used the in vitro data of IL-6-mediated CYP suppression in the PBPK model for prediction of disease-drug interactions involving elevated cytokine levels. As mentioned previously, serum cytokine 
levels are increased in the inflammatory diseases. Although this elevation of cytokines in the patient population is highly variable and dependent on the disease stage, age, and sleep deprivation; it can still impact expression of CYPs (38). In addition, cytokine levels are altered due to administration of various therapeutic proteins. For example, blinatumomab, a bispecific antibody against CD 19, increased cytokines (particularly IL-6 and IL-10) to maximum levels, about six hours after administration (6). However, adalimumab, an antiTNF-a antibody, resulted in reduced levels of pro-inflammatory cytokines (TNF- $a$ and IL-6) (39). Since elevated or reduced cytokine levels can alter the expression of different CYPs, these biologics have the potential to change the PK of the small molecule drugs that are metabolized by the CYPs, resulting in therapeutic protein- drug interactions (40).

Effect of alteration of the model parameters $\left(V_{\max }, K_{m}, F_{g}, F_{u, b}\right)$ on the PK profile was studied (Supplementary Figs. 9 and 10)- $C_{\max }$ and AUC (data not shown) were the major PK parameter sensitive to the change in various model parameters. This indicates that the tested model parameters defined metabolism of MDZ in the liver and intestine and alteration of the values from the original parameter value may impact PK prediction of MDZ.

Plasma protein binding of MDZ is around 95\%. Furthermore, the fraction unbound of MDZ was constant even with changing plasma drug concentration as reported earlier (41).

Alteration of plasma proteins may have a significant impact on MDZ clearance assuming that the only unbound fraction of MDZ can be metabolized by CYP450 enzymes. A protein binding study with human serum albumin and $a-1$-acid glycoprotein solutions showed that MDZ was extensively bound to both (42). Glycosylation of a-1-acid glycoprotein was changed in patients with rheumatoid arthritis (43). These structural changes in the protein may lead to altered binding with drugs. In another report, plasma albumin levels decreased in patients with the inflammatory disease (arthritis). In addition, a-1-acid glycoprotein level increased in the arthritis patients as compared to the healthy control group. The authors also reported changes in the plasma protein binding of propranolol and chlorpromazine in the arthritis patients to establish correlation between changes in plasma protein levels and protein binding of the drugs (44). Therefore, it was pertinent to investigate MDZ protein binding in healthy and GPI-treated mice with inflammation. However, MDZ plasma protein binding was same for the healthy and diseased animals (Table IV). This eliminated the possibility of altered plasma protein levels contributing to differences in clearance for the healthy and diseased mice.

The 'Well-Stirred' model (eq. 3) of gut (31) was used to calculate $f_{u, g}$ using literature values of $\left.Q_{g_{W}}, V_{\text {max-1-OH-MDZ- } g_{W}}, K_{m-1-O H-M D Z-g_{W}}\right)$ and $F_{g}$ (Table IV and V). After PO administration, MDZ is well absorbed $\left(F_{a}=1\right)(21)$. Therefore, low bioavailability $(F=$ 0.062) of MDZ after PO administration may be attributed to the intestinal metabolism. As mentioned in the previous section, in vitro data were not available to define metabolism in the intestines, and hence literature values were used instead (27). In addition, non-CYP3A metabolism of MDZ was defined by the parameters ( $V_{\max -n o n C Y P 3 A-M N Z-g_{W}}$ and $\left.K_{m-n o n C Y P 3 A-M D Z-g_{W}}\right)$ estimated using the semi-PBPK model and healthy-animal PK data.

The 1-OH-MDZ and 4-OH-MDZ are important metabolites of MDZ $(13,15)$. In a mass balance study in humans using radioactive MDZ, $60-70 \%$ of administered dose was 
eliminated via renal route as 1-OH-MDZ-glucuronide, while 4-OH-MDZ and 1,4-diOHMDZ were $\sim 3$ and $\sim 1 \%$, respectively. Urinary excretion of unchanged MDZ was negligible (45). Another study used rats to show that $81 \%$ of the administered dose was recovered in the feces, while $10 \%$ was recovered in the urine (46). In addition, urinary excretion of MDZ had $<1 \%$ contribution according to a clinical study (47). Therefore, in this study, renal clearance of MDZ was excluded from the model. The model substrate MDZ, is mainly cleared via hepatic metabolism. For other drugs with minimum or no hepatic metabolism where renal elimination is a major route of clearance, the semi-PBPK model may not be appropriate or may need modifications to account for non-hepatic metabolism and renal elimination. In addition, the model would require PK data generated in the healthy animals and hepatic in vitro microsomal metabolism data obtained using both the healthy and diseased mice.

Overall, the model successfully predicted MDZ PK in the disease condition. The model may be useful to predict PK of other CYP substrates in the mice with GPI-mediated inflammation. In the drug discovery process, dose selection for the preclinical disease models is usually done using PK data in the healthy animals. The healthy animal PK data may not accurately predict the impact of inflammation or other diseases on the PK of NCEs. The semi-PBPK model may be useful to predict doses for achieving targeted exposure during GPI- mediated inflammation. The model and in vitro data were used to demonstrate this approach of PK prediction. However, the proposed framework of the semi-PBPK model may also be extended to other inflammation models and disease conditions, provided availability of minimal healthy animal PK and in vitro metabolism data that assumes clearance via CYPs.

\section{CONCLUSION}

The in vitro hepatic metabolism, and PK of MDZ were studied during the GPI-mediated inflammation in mice. In addition, serum cytokine levels and hepatic CYP mRNA during GPI-mediated inflammation were examined. The semi-PBPK model predicted PK of MDZ in the diseased state. The model may be used to select doses for mice with GPI-mediated inflammation in order to achieve targeted exposure by correcting for suppression of metabolism due to inflammation. This model may also be used for PK prediction of other drugs after GPI-mediated inflammation.

\section{Supplementary Material}

Refer to Web version on PubMed Central for supplementary material.

\section{ACKNOWLEDGEMENTS}

\footnotetext{
The authors acknowledge Michael Mohutsky for help with the in vitro metabolism work, Tom Kern (Covance Inc.) for conducting in vivo pharmacokinetic experiments, George Searfoss for CYP mRNA measurements, Bridget Morse for suggestions regarding the semi-PBPK model, and Daniel Mudra for critically reading the manuscript and providing suggestions. Eli Lilly provided support for an internship by NV and funded laboratory and animal studies. NV and MLF were partially supported by a grant from NIH (R01CA173292, PI: Forrest) during analysis and development of the model. NV was partially supported by a Higuchi Fellowship and the Department of Pharmaceutical Chemistry, The University of Kansas.
} 
ABBREVIATIONS

\begin{tabular}{ll} 
CAR & Constitutive androstane receptor \\
CYP & Cytochrome P450 \\
DBS & Dried blood spot \\
GPI & Glucose-6-phosphate isomerase \\
HNF-4a & Hepatic nudear factor-4a \\
HLM & Human liver microsomes \\
IV & Intravenous \\
LC-MS & Liquid Chromatography-Mass Spectrometry \\
MDZ & Midazolam \\
MLM & Mouse liver microsomes \\
NCA & Non-compartmental analysis \\
NCE & New chemical entity \\
PBPK & Physiologically based pharmacokinetic \\
PK & Pharmacokinetics \\
PO & Oral \\
PXR & Pregnane X receptor \\
qPCR & Quantitative polymerase chain reaction \\
SCID & Severe combined immune deficient \\
\hline
\end{tabular}

\section{REFERENCES}

1. Morgan E Impact of infectious and inflammatory disease on cytochrome P450-mediated drug metabolism and pharmacokinetics. Clin Pharmacol Ther. 2009;85(4):434-8. [PubMed: 19212314]

2. Frye RF, Schneider VM, Frye CS, Feldman AM. Plasma levels of TNF- $a$ and IL-6 are inversely related to cytochrome $\mathrm{P} 450$-dependent drug metabolism in patients with congestive heart failure. $\mathrm{J}$ Card Fail. 2002;8(5):315-9. [PubMed: 12411982]

3. Coûtant D, Kulanthaivel P, Turner P, Bell R, Baldwin J, Wijayawardana S, et al. Understanding disease-drug interactions in Cancer patients: implications for dosing within the therapeutic window. Clin Pharmacol Ther. 2015;98(1):76-86. [PubMed: 25808023]

4. Robertson G, Iiddle C, Clarke S. Inflammation and altered drug clearance in Cancer: transcriptional repression of a human CYP3A4 transgene in tumor-bearing mice. Clin Pharmacol Ther. 2008;83(6): 894-7. [PubMed: 18388870]

5. Aitken AE, Morgan ET. Gene-specific effects of inflammatory cytokines on cytochrome P450 2C, 2B6 and 3A4 mRNA levels in human hepatocytes. Drug Metab Disposition. 2007;35(9): 1687-93.

6. Xu Y, Hijazi Y, Wolf A, Wu B, Sun YN, Zhu M. Physiologically based pharmacokinetic model to assess the influence of Blinatumomab-mediated cytokine elevations on cytochrome P450 enzyme activity. CPT: pharmacometiics \& systems pharmacology. 2015;4(9):507-15. 
7. Martignoni M, Groothuis GM, de Kanter R. Species differences between mouse, rat, dog, monkey and human CYP-mediated drug metabolism, inhibition and induction. Expert Opin Drug Metab Toxicol. 2006;2(6):875-94. [PubMed: 17125407]

8. Matsumoto I, Zhang H, Yasukochi T, Iwanami K, Tanaka Y, Inoue A, et al. Therapeutic effects of antibodies to tumor necrosis factor-alpha, interleukin-6 and cytotoxic T-lymphocyte antigen 4 immunoglobulin in mice with glucose-6-phosphate isomerase induced arthritis. Arthritis Res Ther. 2008;10(3):R66. [PubMed: 18534002]

9. Palmqvist N, Siller M, Klint C, Sjödin A A human and animal model-based approach to investigating the anti-inflammatory profile and potential of the 5-HT 2B receptor antagonist AMI 030. J Inflamm. 2016; 13(1):20.

10. Gandhi A, Guo T, Shah P, Moorthy B, Chow DL, Hu M, et al. CYP3A-dependent drug metabolism is reduced in bacterial inflammation in mice. BrJ Pharmacol. 2012; 166(7):2176-87. [PubMed: 22394353]

11. Kato R, Yamashita S, Moriguchi J, Nakagawa M, Tsukura Y, Uchida K, et al. Changes of midazolam pharmacokinetics in Wistar rats treated with lipopolysaccharide: relationship between total CYP and CYP3A2. Innate Immun. 2008; 14(5):291-7. [PubMed: 18809653]

12. Kajikawa N, Doi M, Kusaba J-i, Aiba T. Effect of carrageenan-induced acute peripheral inflammation on the pharmacokinetics and hepatic metabolism of midazolam in rats. Drug Metab Pharmacokinet. 2014;29(5):400-6. [PubMed: 24717840]

13. Perloff MD, von Moltke LL, Cotreau MM, Greenblatt DJ. Unchanged cytochrome P450 $3 \mathrm{~A}$ (CYP3A) expression and metabolism of midazolam, triazolam, and dexamethasone in $\mathrm{mdr}(-/-)$ mouse liver microsomes. Biochem Pharmacol. 1999;57(11): 1227-32. [PubMed: 10230766]

14. Samuelsson K, Pickup K, Sarda S, Swales JG, Morikawa Y, Schulz-Utermoehl T, et al. Pharmacokinetics and metabolism of midazolam in chimeric mice with humanised livers. Xenobiotica. 2012;42(11):1128-37. [PubMed: 22642803]

15. Patki KC, von Moltke LL, Greenblatt DJ. In vitro metabolism of midazolam, triazolam, nifedipine, and testosterone by human liver microsomes and recombinant cytochromes p450: role of cyp3a4 and cyp3a5. Drug Metab Disposition. 2003;31(7):938-44.

16. Bockermann R, Schubert D, Kamradt T, Holmdahl R. Induction of a B-cell-dependent chronic arthritis with glucose-6-phosphate isomerase. Arthrit Res Ther. 2005;7(6):R1316-R24.

17. Kamath S, Kummerow F, Narayan KA. A simple procedure for the isolation of rat liver microsomes. FEBS Lett. 1971; 17(1):90-2. [PubMed: 11946004]

18. Elovaara E, Mikkola J, Luukkanen L, Antonio L, Foumel-Gigleux S, Burchell B, et al. Assessment of catechol induction and glucuronidation in rat liver microsomes. Drug Metab Disposition. 2004;32(12): 1426-33.

19. Smith PK, Krohn RI, Hermanson G, Mallia A, Gartner F, Provenzano M, et al. Measurement of protein using bidnchoninic add. Anal Biochem. 1985; 150(1):76-85. [PubMed: 3843705]

20. Granvil CP, Yu A-M, Elizondo G, Akiyama TE, Cheung C, Feigenbaum L, et al. Expression of the human CYP3A4 gene in the small intestine of transgenic mice: in vitro metabolism and pharmacokinetics of midazolam. Drug Metab Disposition. 2003;31(5):548-58.

21. Kuze J, Mutoh T, Takenaka T, Morisaki K, Nakura H, Hanioka N, et al. Separate evaluation of intestinal and hepatic metabolism of three benzodiazepines in rats with cannulated portal and jugular veins: comparison with the profile in non-cannulated mice. Xenobiotica. 2009;39(11):87180. [PubMed: 19845438]

22. Zhang W, Han F, Guo P, Zhao H, Lin ZJ, Huang M-Q, et al. Simultaneous determination of tolbutamide, omeprazole, midazolam and dextromethorphan in human plasma by LC-MS/MSA high throughput approach to evaluate drug-drug interactions. J ChromatogrB. 2010;878(15): 1169-77.

23. Davies B, Morris T. Physiological parameters in laboratory animals and humans. Pharm Res. 1993; 10(7): 1093-5. [PubMed: 8378254]

24. Brown RP, Delp MD, Lindstedt SL, Rhomberg LR, Beliles RP. Physiological parameter values for physiologically based pharmacokinetic models. Toxicol Ind Health. 1997; 13(4):407-84. [PubMed: 9249929] 
25. Kirman C, Hays S, Aylward L, Suh M, Harris M, Thompson C, et al. Physiologically based pharmacokinetic model for rats and mice orally exposed to chromium. Chem Biol Interact. 2012;200(1):45-64. [PubMed: 22981460]

26. Masyuk TV, Ritman EL, LaRusso NF. Hepatic artery and portal vein remodeling in rat liver: vascular response to selective cholangiocyte proliferation. AmJ Pathol. 2003; 162(4): 1175-82. [PubMed: 12651609]

27. Kuze J, Mutoh T, Takenaka T, Oda N, Hanioka N, Narimatsu S. Evaluation of animal models for intestinal first-pass metabolism of drug candidates to be metabolized by CYP3A enzymes via in vivo and in vitro oxidation of midazolam and triazolam. Xenobiotica. 2013;43(7):598-606. [PubMed: 23282066]

28. Barter ZE, Bayliss MK, Beaune PH, Boobis AR, Carlile DJ, Edwards RJ, et al. Scaling factors for the extrapolation of in vivo metabolic drug clearance from in vitro data: reaching a consensus on values of human micro-somal protein and hepatocellularity per gram of liver. Curr Drug Metab. 2007;8(1):33-45. [PubMed: 17266522]

29. Cubitt HE, Houston JB, Galetin A. Prediction of human drug clearance by multiple metabolic pathways: integration of hepatic and intestinal microsomal and cytosolic data. Drug Metab Disposition. 2011;39(5):864-73.

30. Zhang X, Quinney SK, Gorski JC, Jones DR, Hall SD. Semiphysiologically based pharmacokinetic models for the inhibition of midazolam clearance by diltiazem and its major metabolite. Drug Metab Disposition. 2009;37(8):1587-97.

31. Yang J, Jamei M, Yeo KR, Tucker GT, Rostami-Hodjegan A. Prediction of intestinal first-pass drug metabolism. Curr Drug Metab. 2007;8(7):676-84. [PubMed: 17979655]

32. Cleton A, Mazee D, Voskuyl R, Danhof M. Rate of change of blood concentrations is a major determinant of the pharmacodynamics of midazolam in rats. BrJ Pharmacol. 1999; 127(1):227-35. [PubMed: 10369477]

33. Wang J, Xia S, Xue W, Wang D, Sai Y, Liu L, et al. A semi-physiologically-based pharmacokinetic model characterizing mechanism-based auto-inhibition to predict stereoselective pharmacokinetics of verapamil and its metabolite norverapamil in human. Eur J Pharm Sd. 2013;50(3):290-302.

34. Chowdhury F, Williams A, Johnson P. Validation and comparison of two multiplex technologies, Luminex ${ }^{\circledR}$ and mesoscale discovery, for human cytokine profiling. J Immunol Methods. 2009;340(1): 55-64. [PubMed: 18983846]

35. Lu J, Goldsmith M-R, Grulke CM, Chang DT, Brooks RD, Leonard JA, et al. Developing a physiologically-based pharmaco-kinetic model knowledgebase in support of provisional model construction. PLoS Comput Biol. 2016; 12(2):e 1004495.

36. Czerwinski M, Kazmi F, Parkinson A, Buckley DB. Anti-CD28 monoclonal antibody-stimulated cytokines released from blood suppress CYP1A2, CYP2B6 and CYP3A4 in human hepatocytes in vitro. Drug Metab Disposition. 2015;43(1):42-52.

37. Dickmann LJ, Patel SK, Rock DA, Wienkers LC, Slatter JG. Effects of interleukin-6 (IL-6) and an anti-IL-6 monoclonal antibody on drug-metabolizing enzymes in human hepatocyte culture. Drug Metab Disposition. 2011;39(8): 1415-22.

38. Machavaram K, Almond L, Rostami-Hodjegan A, Gardner I, Jamei M, Tay S, et al. A physiologically based pharmacokinetic modeling approach to predict disease-drug interactions: suppression of CYP3Aby IL-6. Clin Pharmacol Ther. 2013;94(2):260-8. [PubMed: 23588308]

39. Charles P, Elliott MJ, Davis D, Potter A, KaldenJR, Antoni C, et al. Regulation of cytokines, cytokine inhibitors, and acute-phase proteins following anti-TNF-a therapy in rheumatoid arthritis. J Immunol. 1999; 163(3): 1521-8. [PubMed: 10415055]

40. Lee J-I, Zhang L, Men AY, Kenna LA, Huang S- M. CYP-mediated therapeutic protein-drug interactions. Clin Pharmacokinet. 2010;49(5):295-310. [PubMed: 20384392]

41. De Vries J, RudiJ, Walter-Sack I, Conradi R. The determination of total and unbound midazolam in human plasma. A comparison of high performance liquid chromatography, gas chromatography and gas chromatography/mass spectrometry. Biomed Chromatogr. 1990;4(1):28-33. [PubMed: 2310839]

42. Reed MD, Myers CM, Blumer JL. Influence of midazolam on the protein binding of ketorolac. Curr Ther Res. 2001;62(8):558-65. 
43. Higai K, Azuma Y, Aoki Y, Matsumoto K. Altered glycosylation of a 1-acid glycoprotein in patients with inflammation and diabetesmellitus. Clin Chim Acta. 2003;329(1):117-25. [PubMed: 12589974]

44. Piafsky KM, Borgä O, Odar-Cederlöf I, Johansson C, Sjöqvist F. Increased plasma protein binding of propranolol and chlorpromazine mediated by disease-induced elevations of plasma al add glycoprotein. N Engl J Med. 1978;299(26): 1435-9. [PubMed: 82206]

45. Heizmann P, Ziegler W. Excretion and metabolism of 14C-midazolam in humans following oral dosing. Arzneimittelforschung. 1981;31(12a):2220-3. [PubMed: 7199324]

46. Woo GK, Williams T, Kolis S, Warinsky D, Sasso G, Schwartz M. Biotransformation of [14C] midazolam in the rat in vitro and in vivo. Xenobiotica. 1981; 11(6):373-84. [PubMed: 7293228]

47. Thummd KE, O'shea D, Paine MF, Shen DD, Kunze KL, Perkins JA et al. Oral first-pass elimination of midazolam involves both gastrointestinal and hepatic CYP3A-mediated metabolism. Clin Pharmacol Ther. 1996;59(5):491-502. [PubMed: 8646820] 


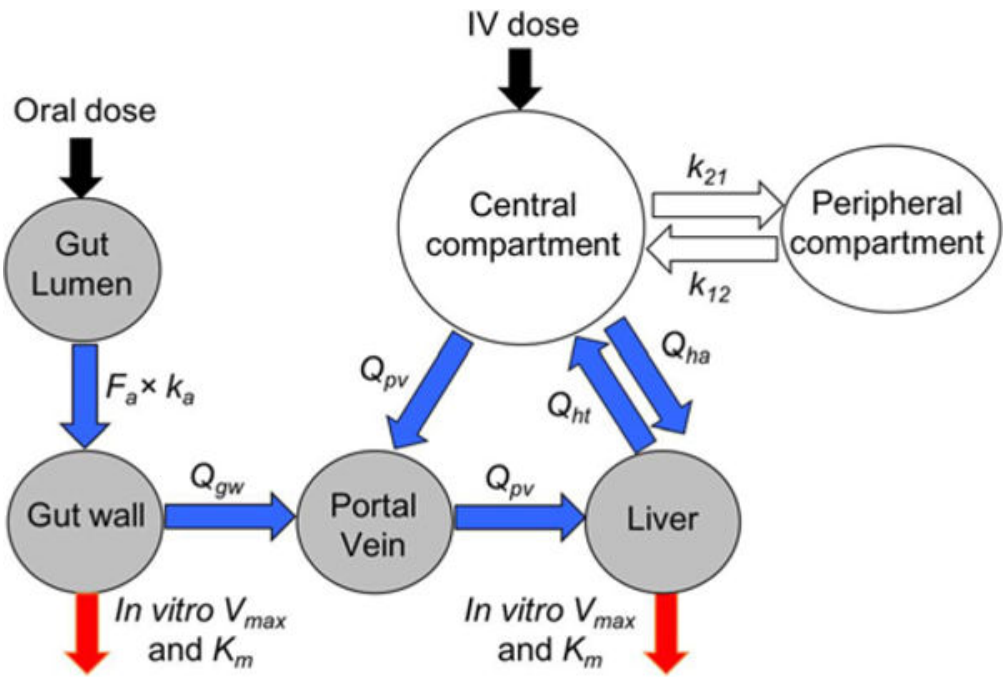

Fig. 1.

Schematic representation of the semi-PBPK model. 

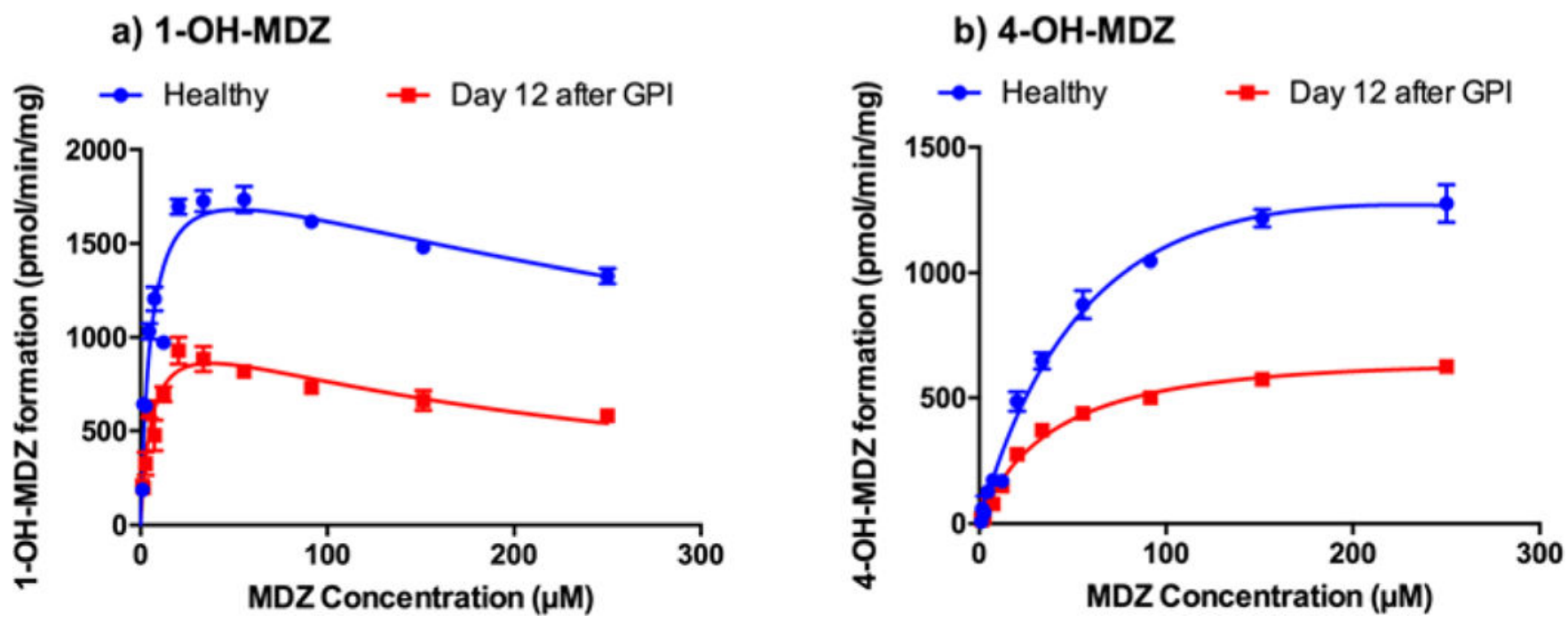

Fig. 2.

Rate of metabolite formation with increasing MDZ concentration in MLM prepared from the healthy and GPI-treated mice a) 1-OH-MDZ and b) 4-OH-MDZ. MLM were prepared using livers collected from the healthy mice and on day 12 after GPI treatment. Lines indicate fitted metabolite formation kinetics. Experimental values are represented as filled circles or squares with standard deviation. $(n=3)$. 
a) Observed Pharmacokinetics (IV-MDZ, $1 \mathrm{mg} / \mathrm{kg}$ )

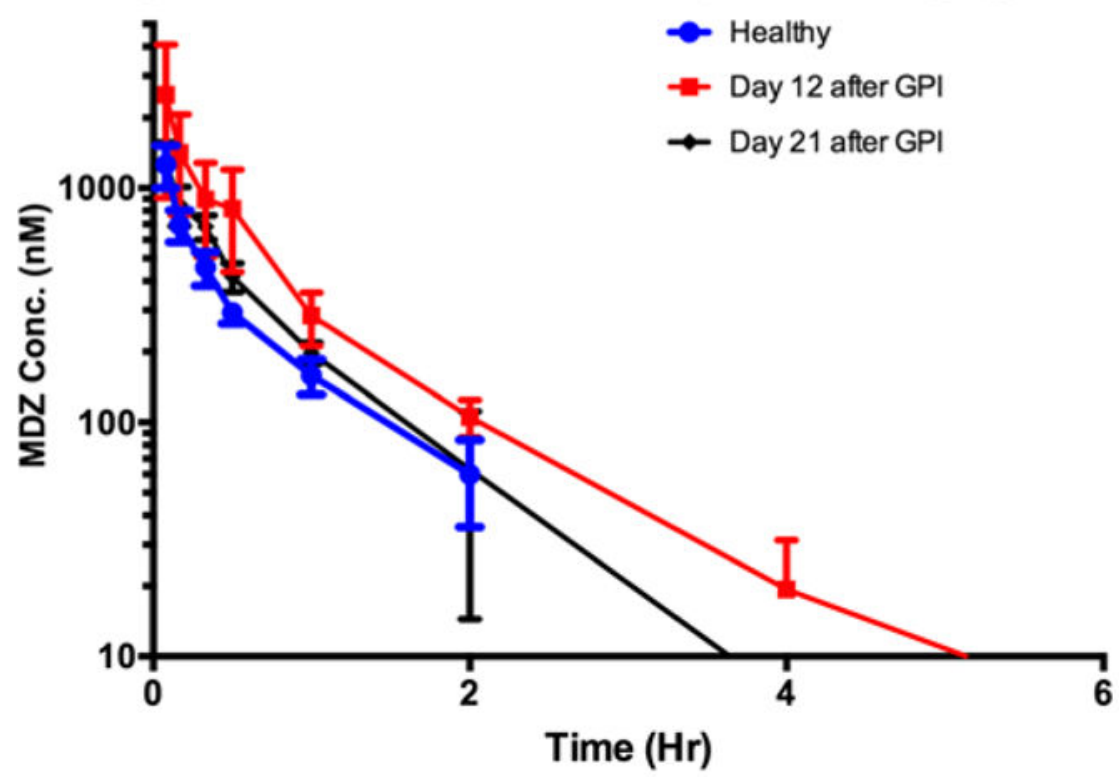

b) Observed Pharmacokinetics (PO-MDZ, $5 \mathrm{mg} / \mathrm{kg}$ )

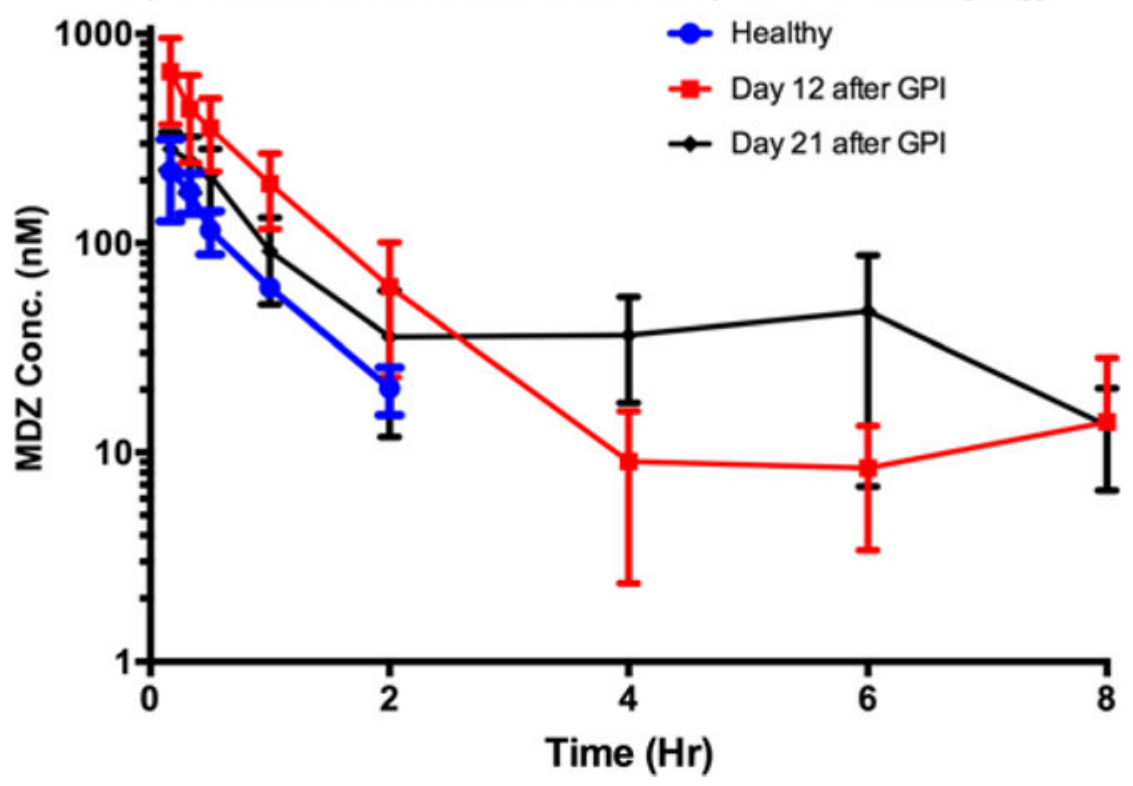

Fig. 3.

Observed pharmacokinetic profiles for a) IV (1 mg/kg) and b) PO (5 mg/kg) MDZ administration. Observed $M D Z P K$ represeted as filled circles or squares with standard deviation $(n=4)$. 
a) Observed vs Predicted (IV-MDZ, $1 \mathrm{mg} / \mathrm{kg}$ )

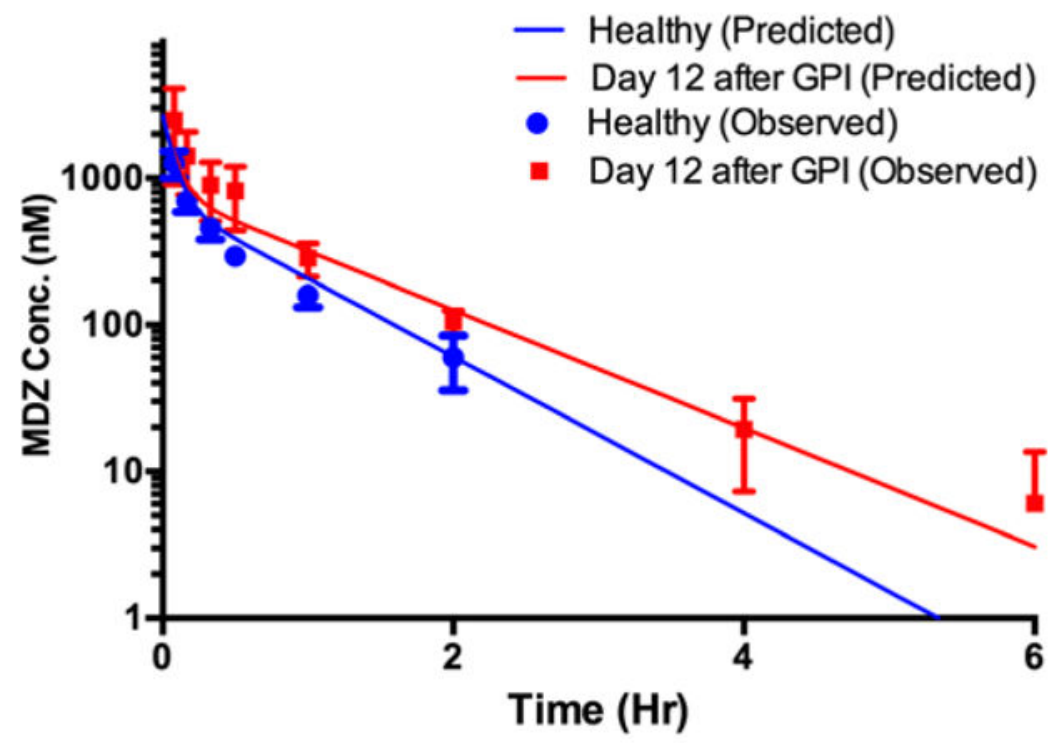

\section{b) Observed vs Predicted (MDZ-PO, $5 \mathrm{mg} / \mathrm{kg}$ )}

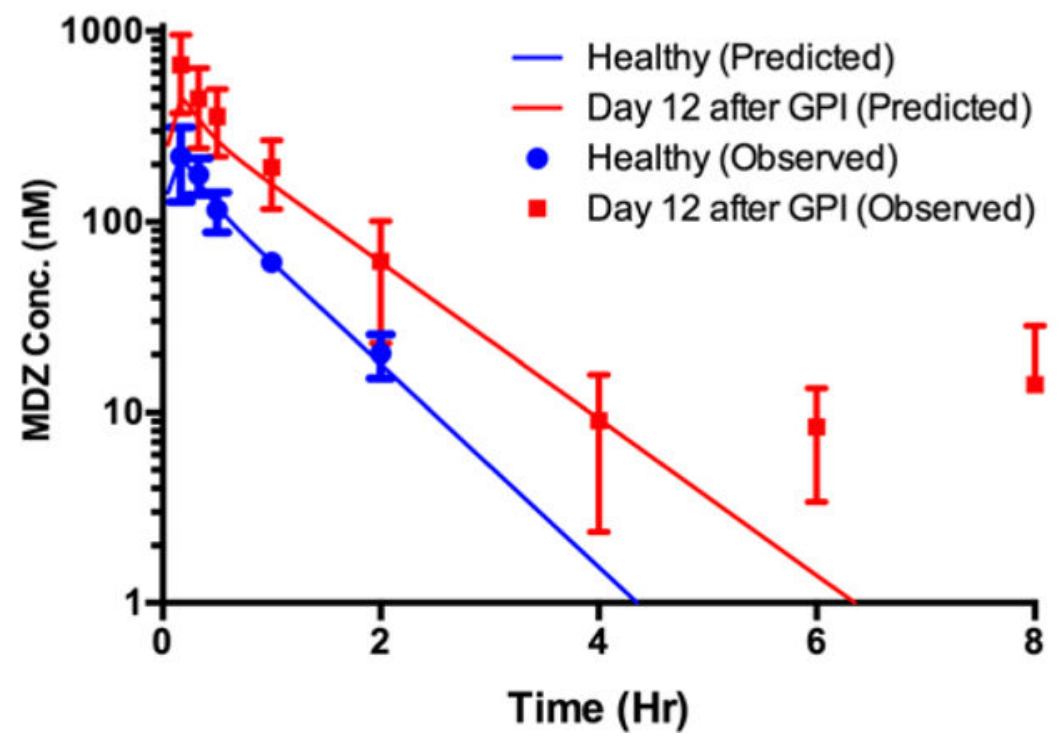

Fig. 4.

Observed and the model predicted PK profiles for a) IV (1 m/kg) and b) PO (5 mg/kg). The observed values represented as mean and standard deviation. 
a)

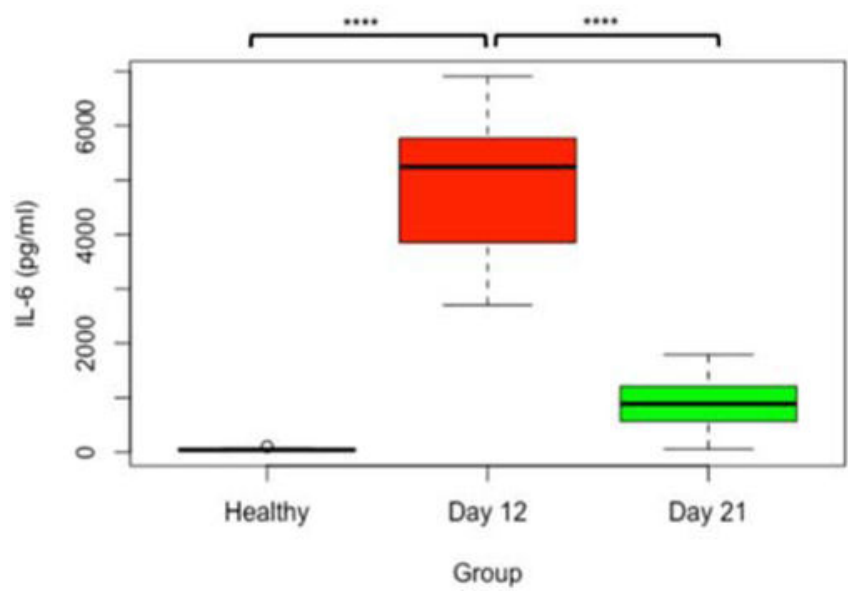

b)

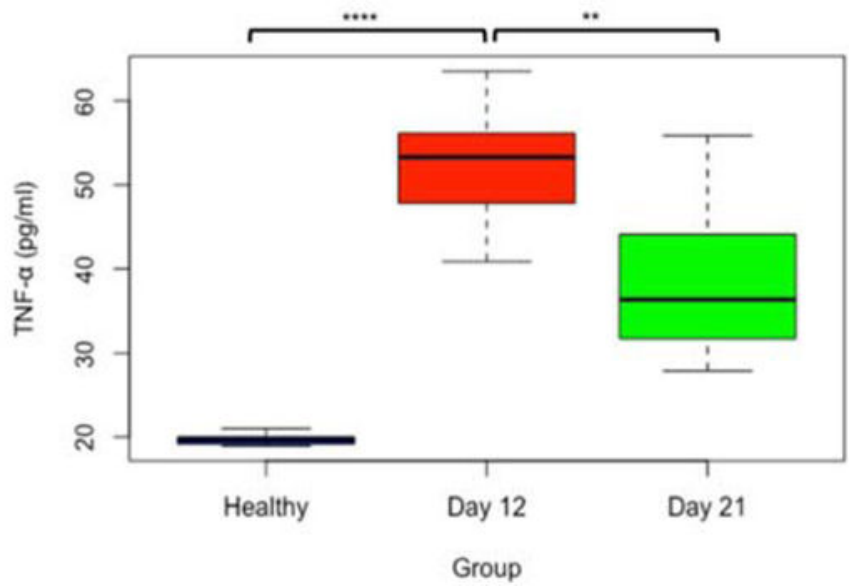

Fig. 5.

Box-plot representation of the serum cytokine levels and statistical comparison for healthy mice, day 12 and day 21 after GPI treatment to mice, a) IL-6 and b) TNF-a. Box-plot showing first and third quartiles, mean and renge. NS: Not Significant, ****:P $\leq$ $0.0001, * *: P$ $\$ 0.01$ (ANOVA and Tukey's test) 
a)

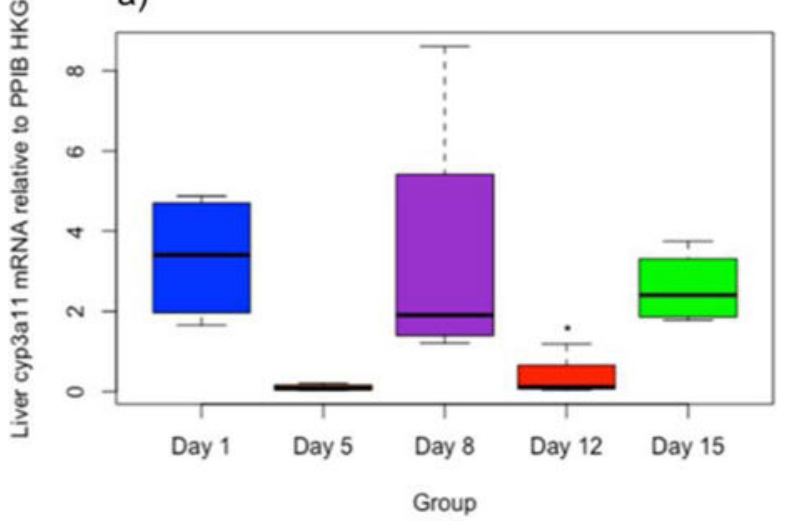

b)

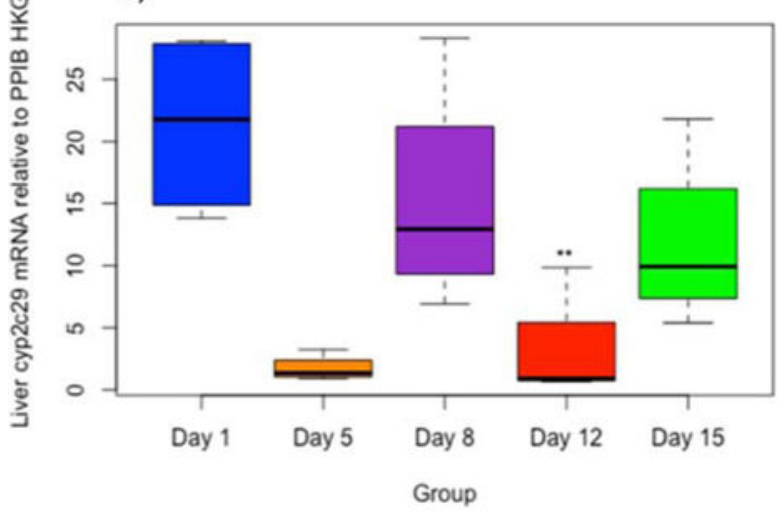

c)

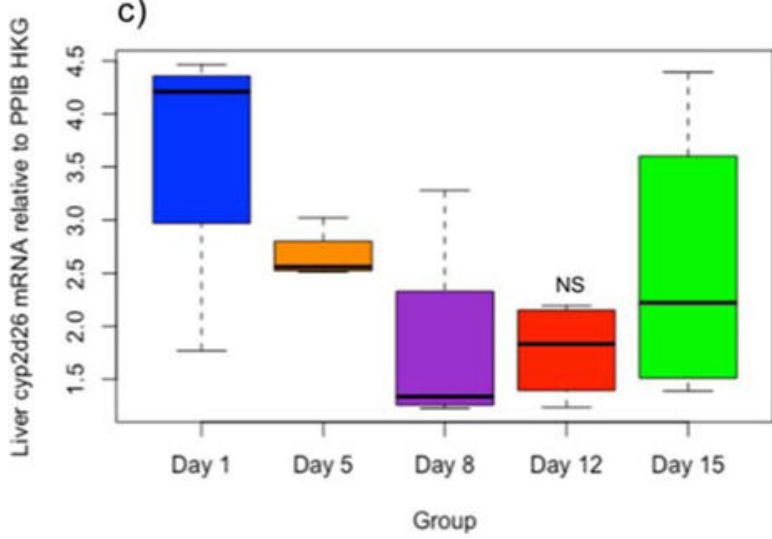

Fig. 6.

Box-plot representation of a) cyp3a11, b) cyp2c29 and c) cyp2d26 mRNA levels in mouse livers on day 1, 5, 8, 12, and 15 after GPI treatment. Box-plot showing first and third quartiles, mean and range. NS: Not significant, *: $P \leq 0.05$, **: $P \leq 0.01$ (Unpaired T-test was used to compare mRNA levels on day 1 and day 12). 

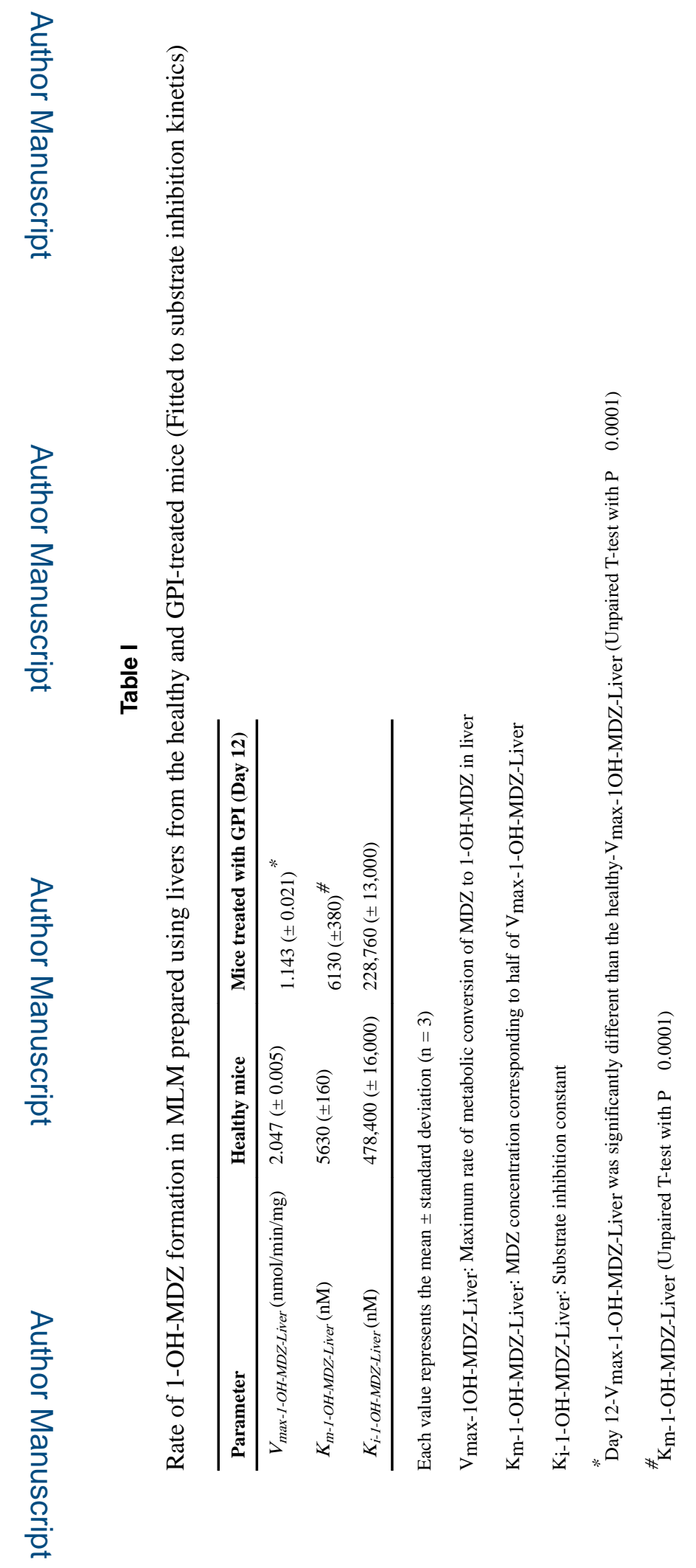

Pharm Res. Author manuscript; available in PMC 2019 August 12. 


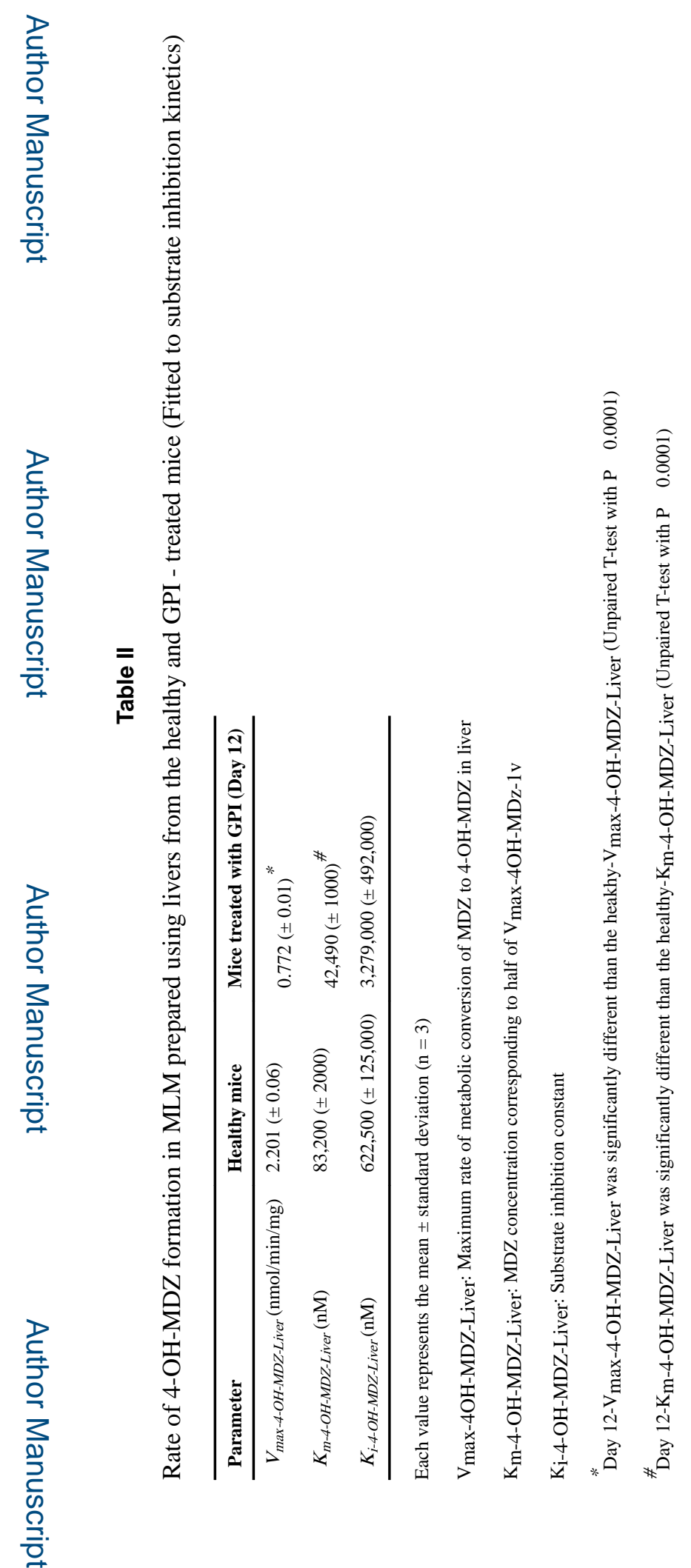

Pharm Res. Author manuscript; available in PMC 2019 August 12. 


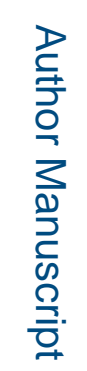

D
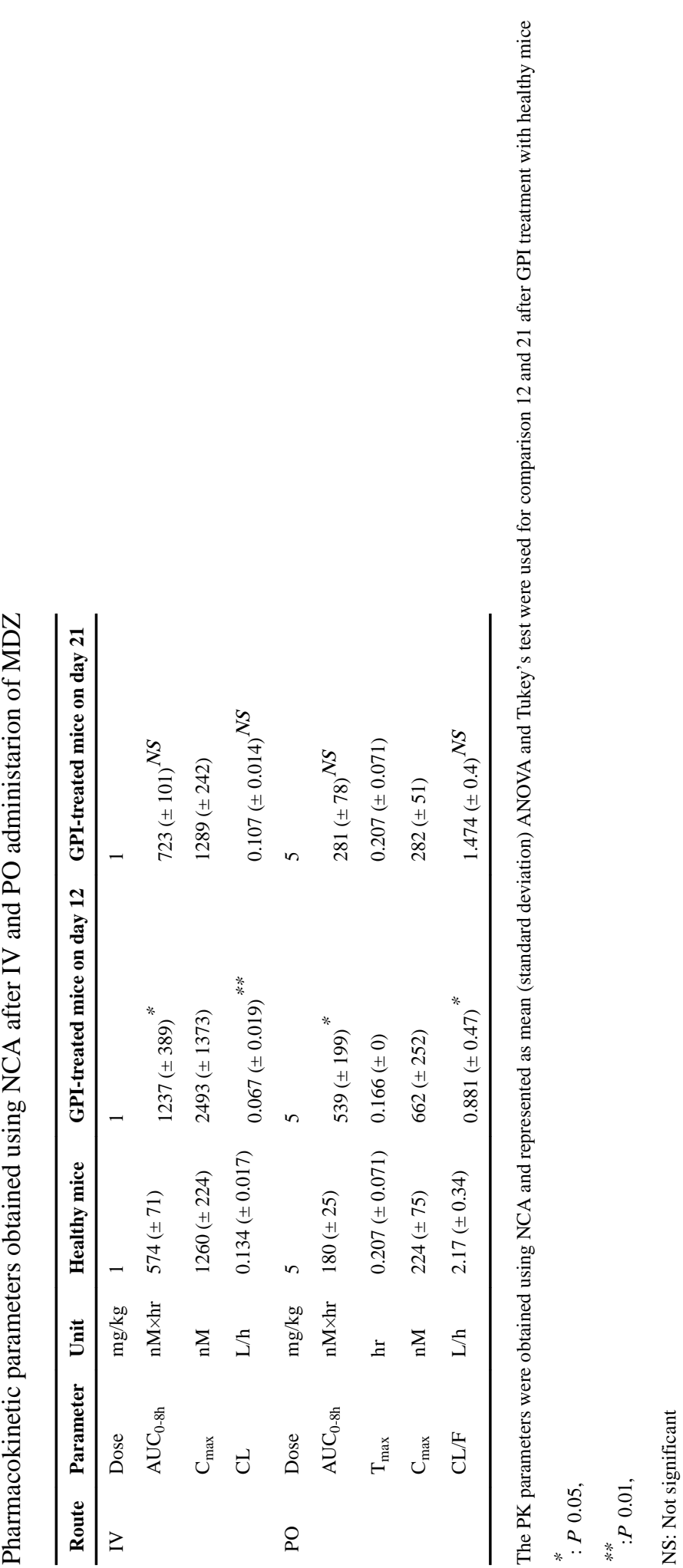

Pharm Res. Author manuscript; available in PMC 2019 August 12. 


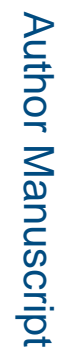

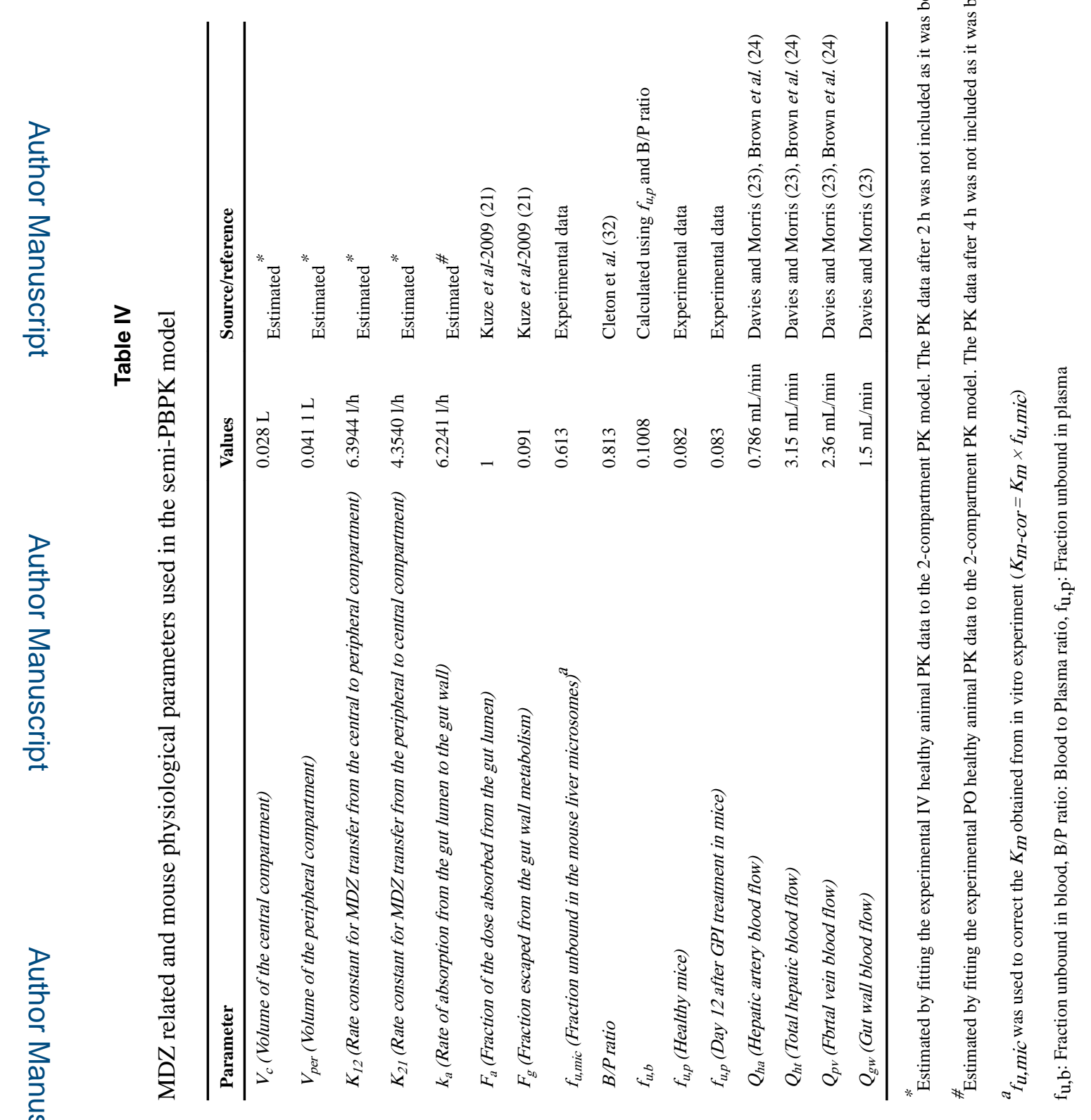




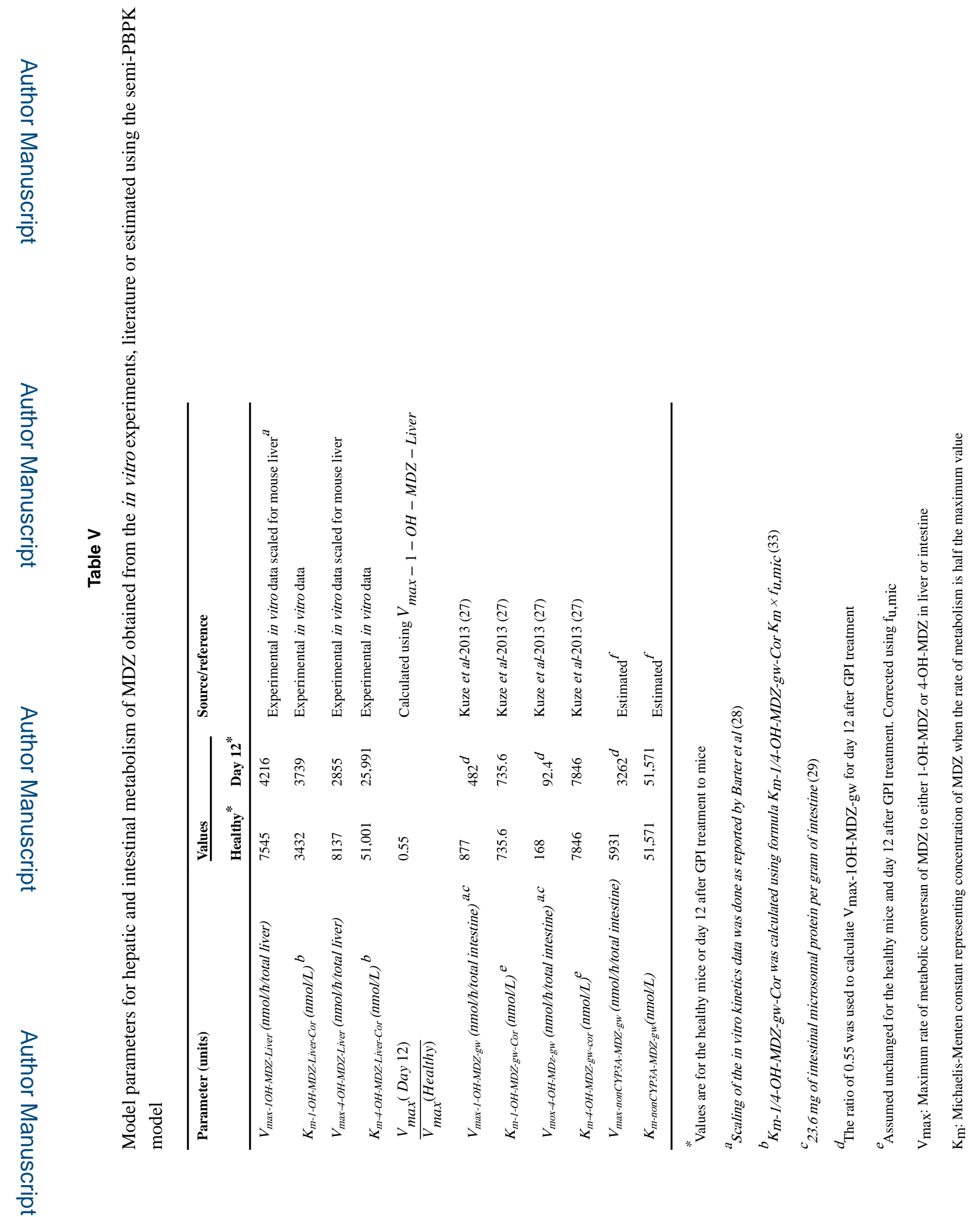

Pharm Res. Author manuscript; available in PMC 2019 August 12. 
